\title{
Prevalence of Obesity and Overweight among Adults in the Middle East Countries from 2000 to 2020: A Systematic Review and Meta-Analysis
}

\author{
Hassan Okati-Aliabad $\left(D,{ }^{1}\right.$ Alireza Ansari-Moghaddam ${ }^{(D)},{ }^{1}$ Shiva Kargar $\left(\mathbb{D},{ }^{2}\right.$ \\ and Neda Jabbari $\mathbb{B D}^{3}$ \\ ${ }^{1}$ Health Promotion Research Center, Zahedan University of Medical Sciences, Zahedan, Iran \\ ${ }^{2}$ MSc of Epidemiology, Gerash University of Medical Sciences, Gerash, Iran \\ ${ }^{3}$ Department of Environment Health Engineering, School of Health, Zahedan University of Medical Sciences, Zahedan, Iran
}

Correspondence should be addressed to Shiva Kargar; shivakargar@yahoo.com

Received 15 July 2021; Accepted 17 January 2022; Published 3 February 2022

Academic Editor: Nunzio Velotti

Copyright (C) 2022 Hassan Okati-Aliabad et al. This is an open access article distributed under the Creative Commons Attribution License, which permits unrestricted use, distribution, and reproduction in any medium, provided the original work is properly cited.

\begin{abstract}
Background. Obesity has become a significant public health issue worldwide, and it is a major risk factor for many noncommunicable diseases. This systematic review aimed to identify the prevalence of obesity and overweight in the Middle East region and different countries in this region. Materials and Methods. PubMed, Google Scholar, and MEDLINE databases were searched from 2000-2020 to identify relevant studies in the Middle East area. The survey was carried out using combinations of Medical Subject Headings (Mesh) keywords like "body mass index", "obesity", "overweight", "prevalence", "Middle-East", and "Countries in the Middle East area". Analysis of the data was done using STATA-14, and a random-effects model was used to estimate the pooled prevalence. Results. A total of 101 studies with 698905 participants have been identified that met inclusion criteria for this meta-analysis. The pooled estimates of the prevalence of obesity and overweight in the Middle East area were 21.17 (95\% CI: 17.05-26.29) and 33.14 (95\% CI: 26.87-40.87), respectively. The findings showed that obesity prevalence increased with age so that the highest prevalence of obesity and overweight was observed in people $>40$ years old. Obesity prevalence in the Middle East area remained steady between 2000-2006 and 2014-2020 (23\%). During these time intervals, the prevalence of overweight decreased from 34.83 (95\% CI: 32.40-37.45) to 32.85 (95\% CI: 31.39-34.38). Conclusions. Despite the relative stabilization of the overweight and obesity trend in the Middle East, current interventions to combat the overweight epidemic need to be maintained and strengthened because the prevalence of overweight and obesity in this region is still very high. The prevalence of obesity increases with age so that people over 40 have the highest percentage of obesity and overweight. Therefore, implementing intervention programs to prevent and control obesity and overweight in the Middle East is essential.
\end{abstract}

\section{Introduction}

Obesity and overweight are health problems that indicate excessive and abnormal accumulation of body fat and lead to adverse health effects [1]. Epidemiological studies have identified obesity and overweight as risk factors for several diseases, including diabetes, various cancers, cardiovascular disease, and hypertension [2].

The increasing prevalence of high BMI and its resulting mortality threaten people's health in many countries. In addition, it causes destructive health effects and financial burden on people and society $[3,4]$. The leading causes of the increase in obesity and overweight in the Eastern Mediterranean (EMRO) are lifestyle changes, including unhealthy eating habits, physical inactivity, and cultural, social, and economic changes $[5,6]$. On the other hand, using a plantbased diet and physical activity in daily life reduces the risk of obesity [7]. Kuwait, Qatar, and Libya, the three EMRO countries, were among the top ten countries with the highest prevalence of obesity in the world in 2013 [8]. 
The body mass index (BMI) is a simple index to classify overweight and obesity in adults and is defined as weight in $\mathrm{kg} /$ height in $\mathrm{m}^{2}$. Individuals with a $\mathrm{BMI} \geq 30 \mathrm{~kg} / \mathrm{m}^{2}$ are considered obese, and individuals with a BMI between 25 and $29.9 \mathrm{~kg} / \mathrm{m}^{2}$ are considered overweight [9]. Studies show that with age, BMI increases, which is more common in women than men [10].

Up-to-date information on the level and trend of overweight and obesity is needed to prioritize measures to prevent and control weight gain and obesity by health policymakers. Therefore, this systematic review aims to estimate the prevalence of obesity and overweight in general and based on countries in the Middle East. The study also evaluated the attributable risk of obesity-related cardiovascular disease populations in the Middle East.

\section{Method}

2.1. Search Strategy. Preferred Reporting Items for Systematic Reviews and Meta-Analyses (PRISMA) standards were used when conducting this systematic review [11]. A literature search was performed in the online database including Google Scholar, PubMed, and MEDLINE to find the relevant article published between 2000 and 2020. The investigation was done using keyword combinations Medical Subject Headings (Mesh) such as "body mass index", "obesity", "overweight", "prevalence", "Middle-East”, and "Countries in the Middle East area". Two authors worked separately on the literature search.

2.2. Inclusion and Exclusion Criteria. The following are the criteria for including articles in the meta-analysis:

(1) Studies have defined a BMI of $\geq 30 \mathrm{~kg} / \mathrm{m}^{2}$ as obesity and a BMI of $25-29.9 \mathrm{~kg} /$ as overweight

(2) The classification of overweight and obese people was clearly defined

(3) Cross-sectional population-based studies were performed between 2000 and 2020 that reported the prevalence of obesity and overweight

(4) Adults over the age of 15 were eligible to participate in the studies

Studies were excluded from the meta-analysis if they were not published in English and if they focused on children and adolescents and populations with specific conditions, such as hypertension, diabetes, and cancer. In addition, studies that provided the only frequency of obesity and overweight, with no data to calculate the $95 \%$ confidence interval and mixed reporting of obesity and overweight were excluded.

\section{Study Selection and Data Extraction}

3.1. Data Extraction. All articles identified in databases were screened based on keyword, title, and abstract by two researchers independently. Then, relevant articles were assessed, and data extraction was done from the eligible articles and information stored into Microsoft Excel using a checklist created by the researcher.
Data extracted for study characteristics contained the following items: names of authors, year of publication, sample size, gender, age, study setting (country, urban/rural), the prevalence of obesity, overweight, and body mass index mean and its 95\% confidence interval. Some studies, however, did not report confidence intervals. As a result, the following equation was used to calculate the relevant confidence intervals for each point estimation:

$$
p+\frac{z^{2 \alpha / 2}}{2 n} \pm z \frac{\sqrt{p(1-p) \pm z^{2 \alpha / 2} / 4 n}}{\left(1+z^{2 \alpha / 2} / n\right)} .
$$

3.2. Statistical Analysis. The random-effects models were used to generate pooled estimates. I-square and $Q$ figures were also used to look at potential sources of heterogeneity.

The population attributable risks for cardiovascular diseases such as coronary heart disease (CHD), heart failure (HF), and atrial fibrillation (AF) associated with obesity were calculated by prevalence estimates of the obesity in this meta-analysis and the equation: $\mathrm{PAR}=P \quad(\mathrm{RR}-1) / P$ $(\mathrm{RR}-1)+$. The RR was obtained from previously published recent meta-analyses that assessed the association between obesity and the disease listed above.

Therefore, the relative risk (RR) and 95\% CI for atrial fibrillation (AF) were considered 1.51 (1.35-1.68) [12] and odd ratio (OR) and 95\% CI for the association between obesity and coronary heart disease (CHD) and heart failure (HF) were considered 1.20 (1.02-1.41) and 1.62 (1.32-1.99), respectively $[13,14]$.

\section{Result}

4.1. Selection of Study and Characteristics. In the primary search, 1037 articles were identified from databases, of which 230 duplicate articles were excluded. In the first phase (assessing title and abstract), 533 articles were removed due to not being a cross-sectional study design, unrelated title, out of the Middle East scope and review article nature. Finally, 274 articles were assessed in full text; of these, 101 articles met the inclusion criteria in this systematic review and meta-analysis. The flowchart of the study selection process and the frequency of factors for exclusion are outlined in Figure 1.

The studies were performed in 17 Middle East countries: Turkey (16 reports), Iran (11), Kuwait (9), Israel (2), Saudi Arabia (11), Oman (4), Palestine (6), Yemen (1), United Arab Emirates (5), Syria (2), Lebanon (6), Iraq (7), Cyprus (2), Bahrain (2), Jordan (8), and Egypt (8).

A total of 698905 participants aged $>15$ years were included in this systematic review. Studies had a range of sample sizes from 2500 to 257555 . The articles were published between 2000 and 2020, including 18 articles during 2000-2006, 40 articles during 2007-2013, and 43 articles during 2014-2020. Moreover, four studies assessed the prevalence of obesity and overweight on only men and thirteen studies on only women. Table 1 summarizes the characteristics of the articles that were used in the study. 


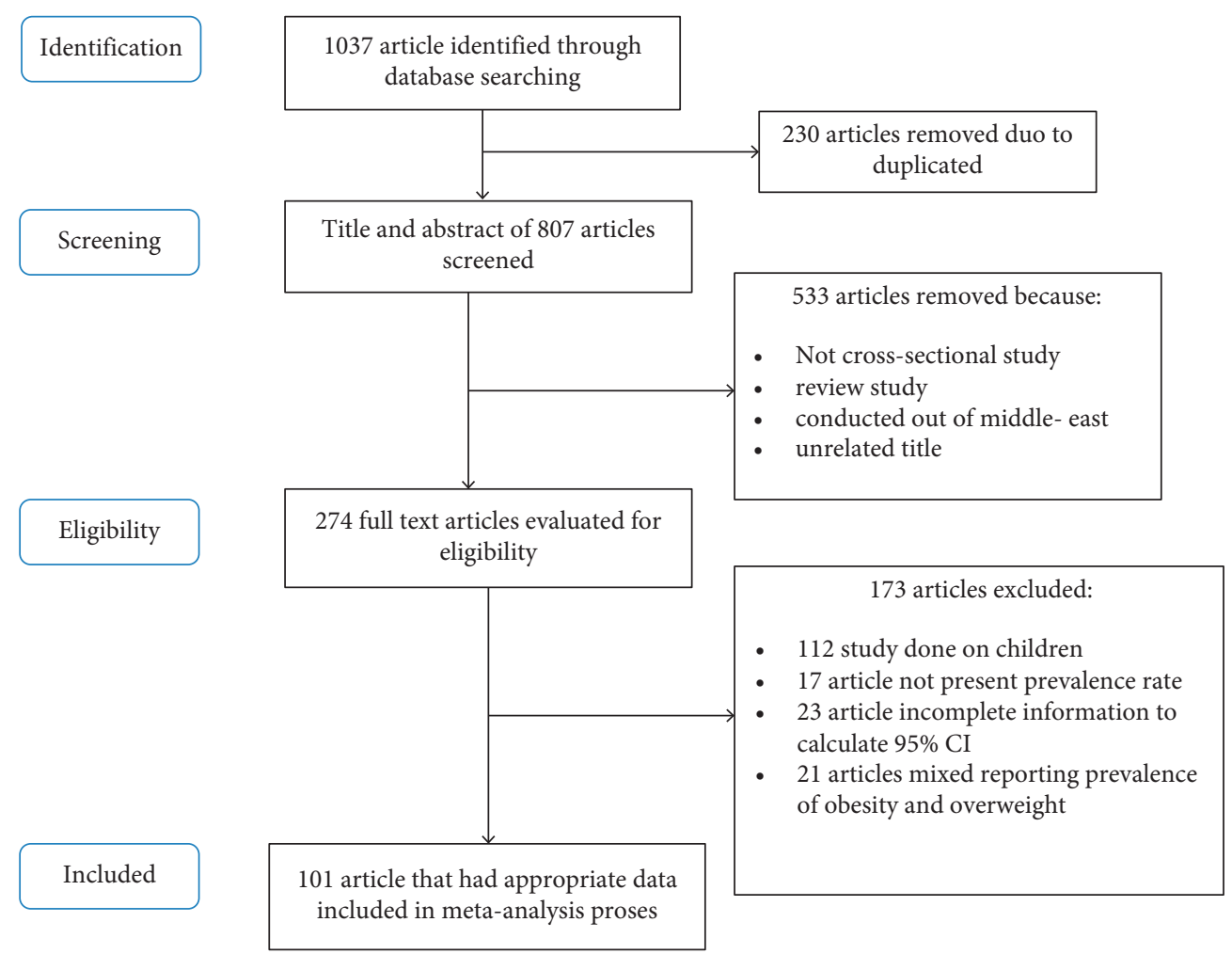

FIGURE 1: Flowchart of the study selection process.

4.2. Prevalence of Overweight and Obesity. Overall, the pooled estimates of the prevalence of obesity and overweight in the Middle East countries were 21.17 (95\% CI: 17.05-26.29) and 33.14 (95\% CI: 26.87-40.87), respectively (Figure 2). However, some heterogeneity was observed between the results of the studies $(p<0.001)$. The range of prevalence of obesity in the Middle East region was between 40.62 (35.85-46.03) in Syria and 8.80 (95\% CI: 7.70-10.00) in Yemen. Also, the range of prevalence of overweight among adults in the Middle East region was between 62.10 (95\% CI: 60.30-63.90) in Israel and 23.50 (95\% CI: 22.00-25.20) in Yemen.

Based on results of sex-specific subgroup analyses, the prevalence of obesity was significantly higher in women, 25.40 (95\% CI: 23.66-27.27), than in men, 19.86 (95\% CI: $17.60-22.40)(p=0.001)$. In contrast, men were more likely to be overweight than women, with a prevalence of 37.80 (95\% CI: 36.20-39.47) compared to 31.24 (95\% CI: 29.96-32.57) $(p<0.001)$.

For residency-specific subgroup analyses, although the rural population had a higher prevalence of obesity and a lower prevalence of overweight than the urban population, it was not statistically significant $(p=0.59, p=0.77)$. The findings of age-specific subgroup studies revealed that obesity increased with age, peaking in the 50-59 and 60-69 age ranges. In addition, the 40-49 and 60-69 age groups had the highest prevalence of overweight (Table 2).

4.3. Time Trends in Obesity and Overweight by Country and Gender. Table 3 depicts the prevalence of obesity and overweight in the Middle Eastern countries from 2000 to 2020. From 2000 to 2006, the highest prevalence of obesity was in Saudi Arabia, 39.6 (95\% CI: 37.9-41.3), and Syria, 38.2 (95\% CI: 36.0-40.3). Moreover, from 2014 to 2020, the highest prevalence of obesity was in Oman, 67.81 (95\% CI: 65.22-70.51), and Syria, 43.4 (95\% CI: 40.2-46.6). Concerning the prevalence of overweight, from 2000 to 2006, the highest prevalence was observed in Kuwait, 44.85 (95\% CI: 38.74-51.93), and Iran, 43.3 (95\% CI: 37.6-49.1). Despite this, from 2014 to 2020, the highest prevalence was in Jordan, 39.94 (95\% CI: 33.98-46.95), and the United Arab Emirates, 39.81 (95\% CI: 33.66-47.08).

Overall, in the Middle East region, obesity prevalence remained stable from 2000 to 2006 and 2014 to 2020, with an average prevalence of 23 percent. However, the prevalence of overweight decreased from 34.83 (95\% CI: 32.40-37.45) to 32.85 (95\% CI: 31.39-34.38) during these time intervals.

The sex-specific subgroup prevalence showed that in women, the prevalence of obesity and overweight decreased from 26.62 (95\% CI: $22.93-30.90)$ and 32.30 (95\% CI: 29.84-34.96) during 2000 to 2006 to 23.15 (95\% CI: 20.85-25.70) and 32.85 (95\% CI: 31.39-34.38) during 2014 to 2020, respectively.

The prevalence of obesity in men increased from 20.08 (95\% CI: 16.24-24.82) from 2000 to 2006 to 23.48 (95\% CI: 20.26-27.20) from 2014 to 2020. However, the overweight prevalence was stable at these periods (39\%).

4.4. Population Attributable Risk of Cardiovascular Disease for Obesity. Table 4 presents Population Attributable Risk 


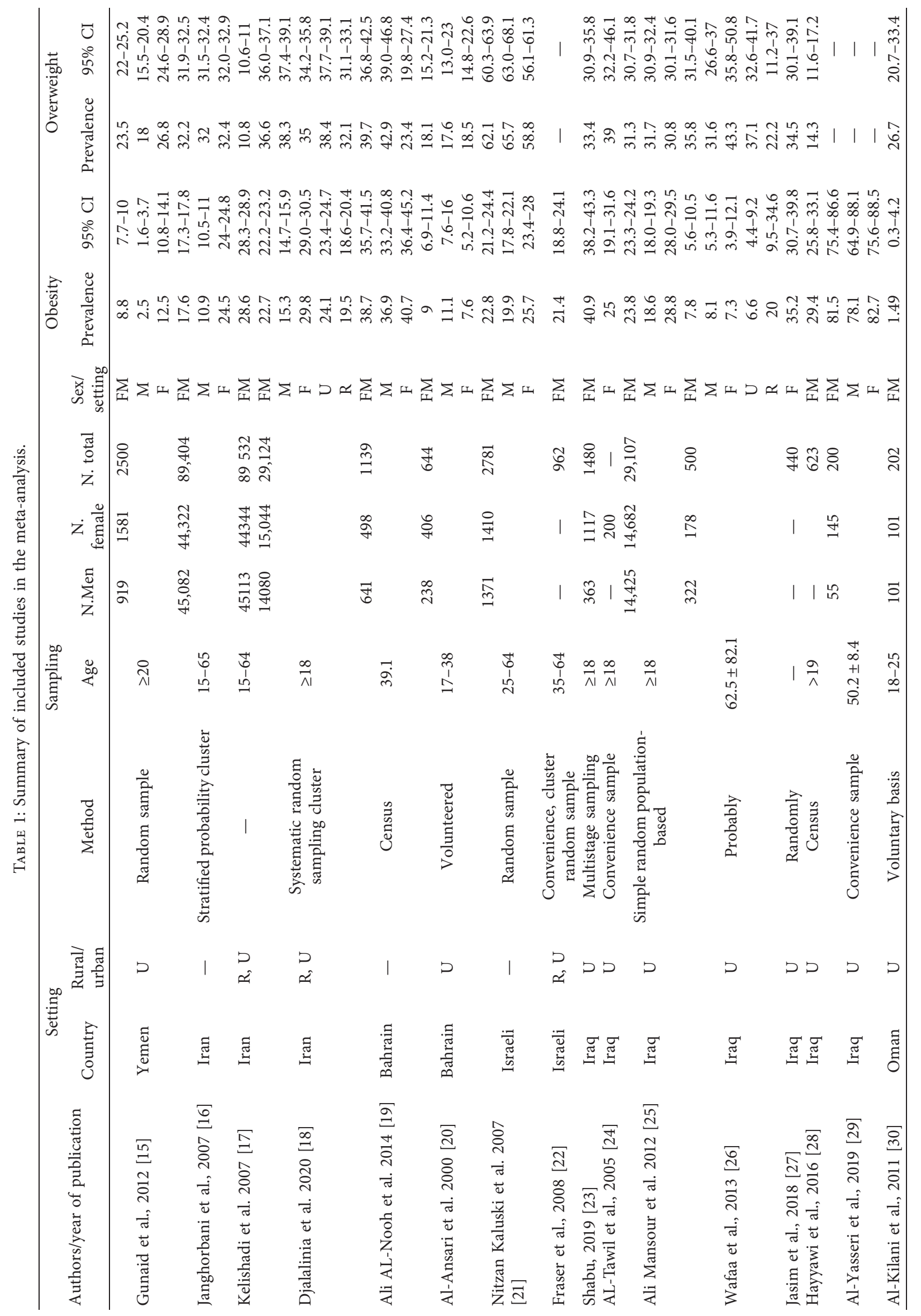




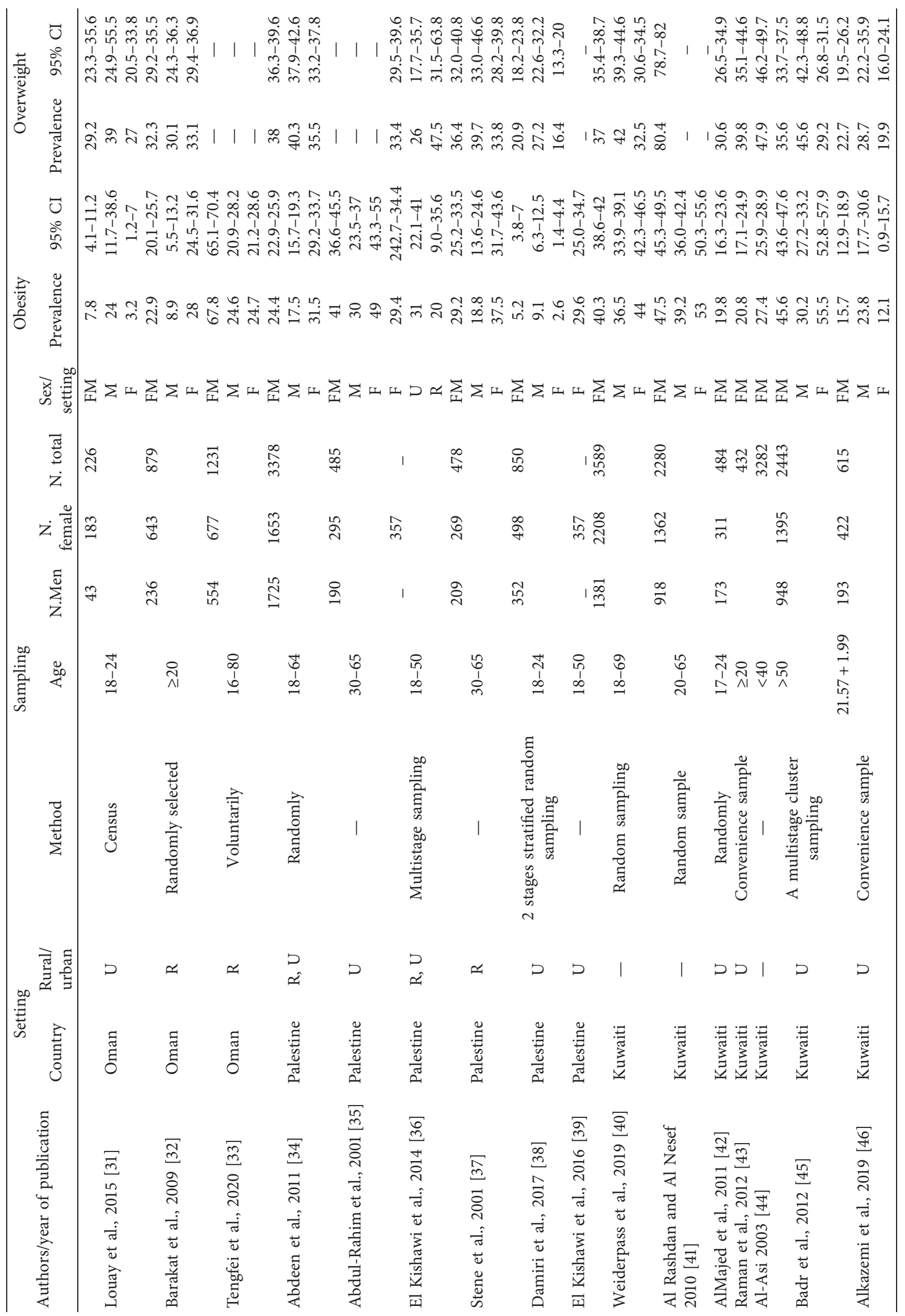




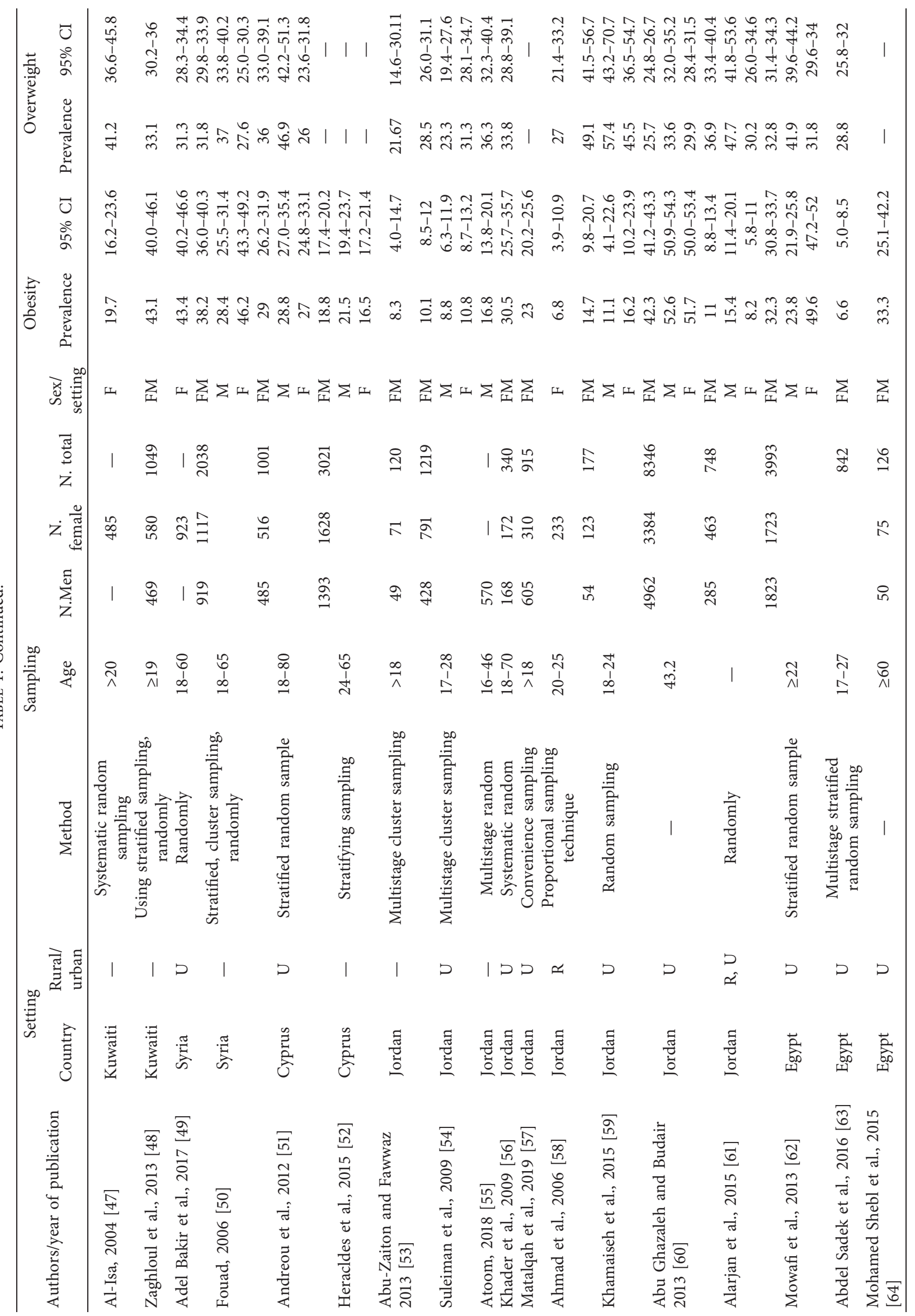




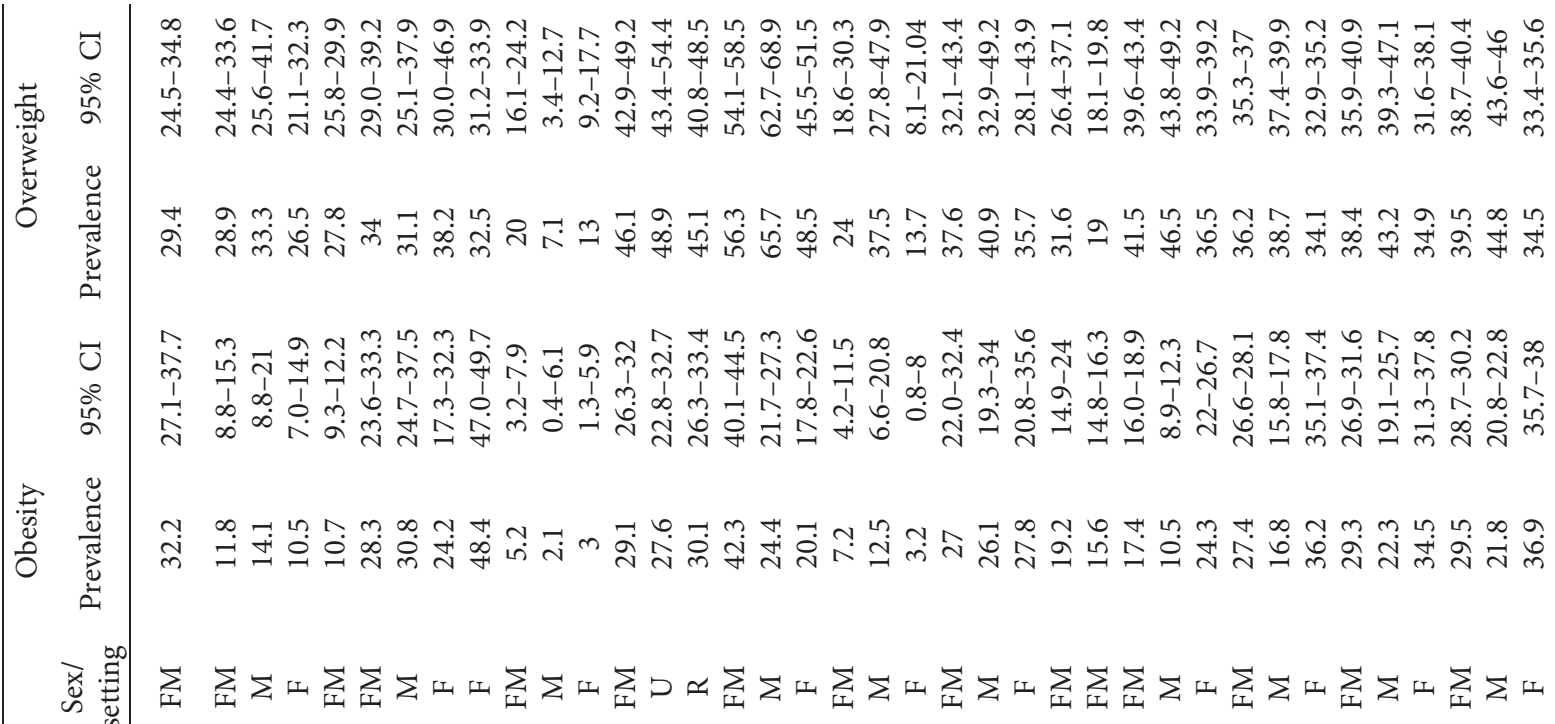

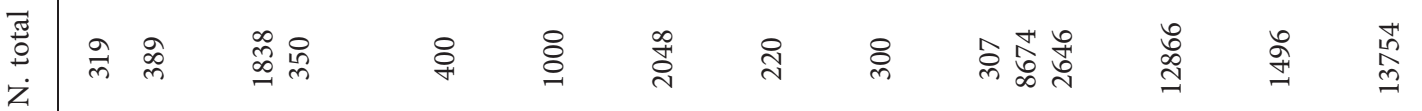

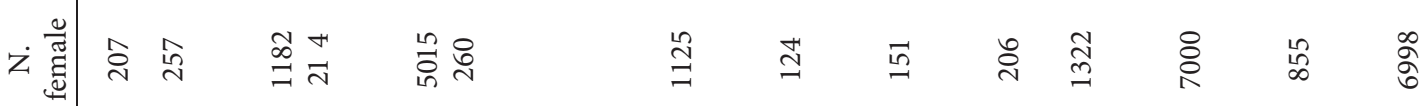

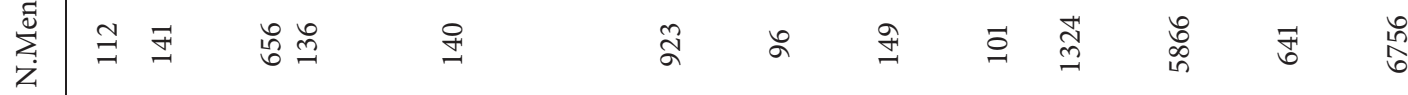

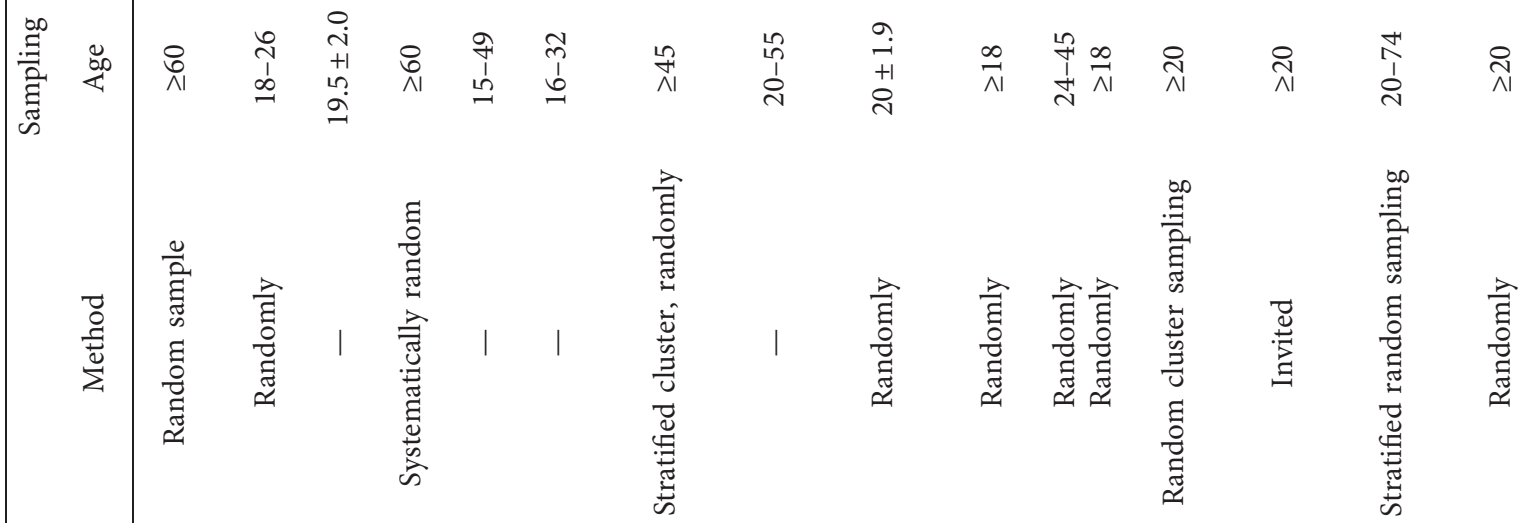

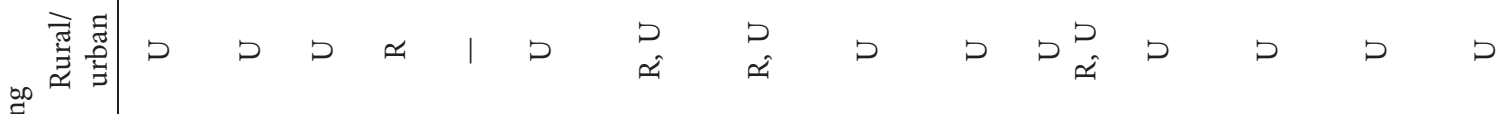

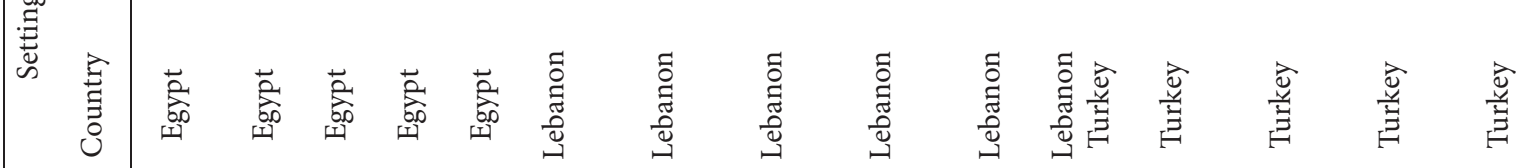

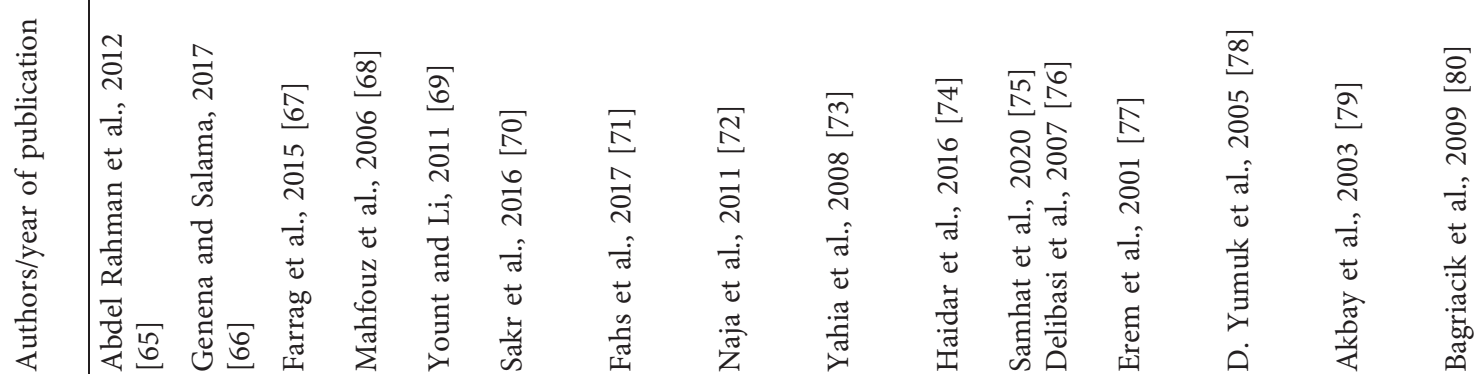




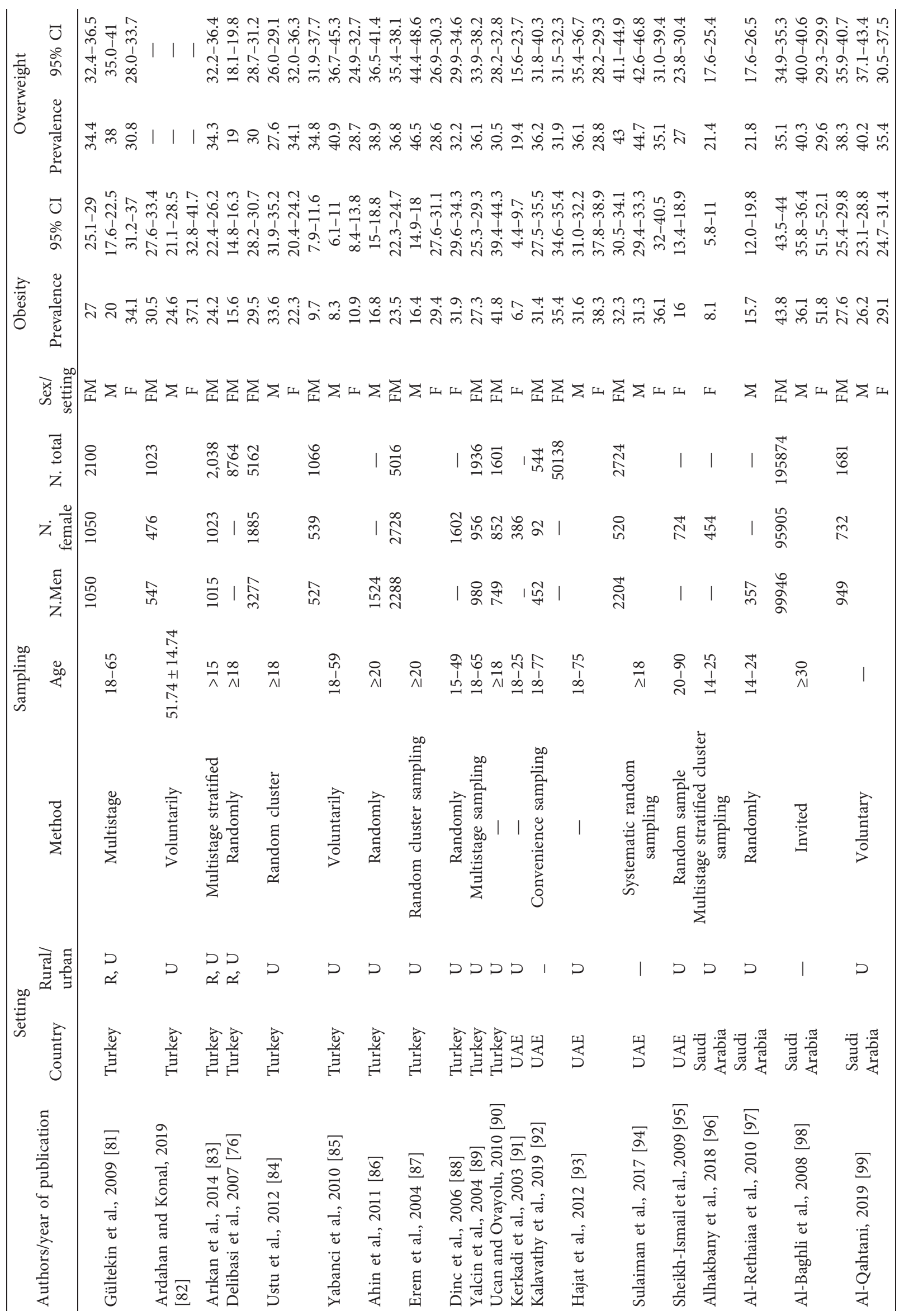




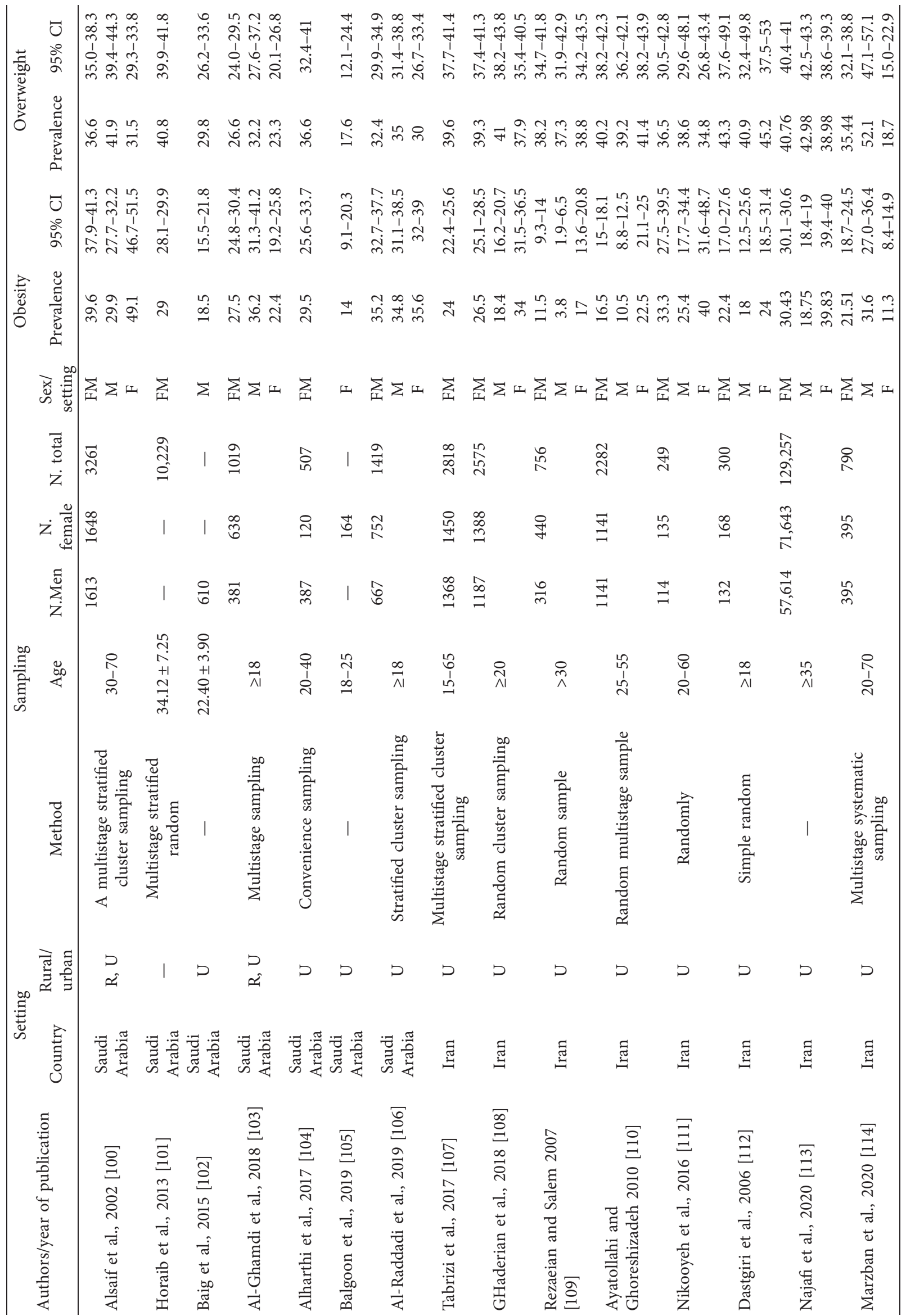




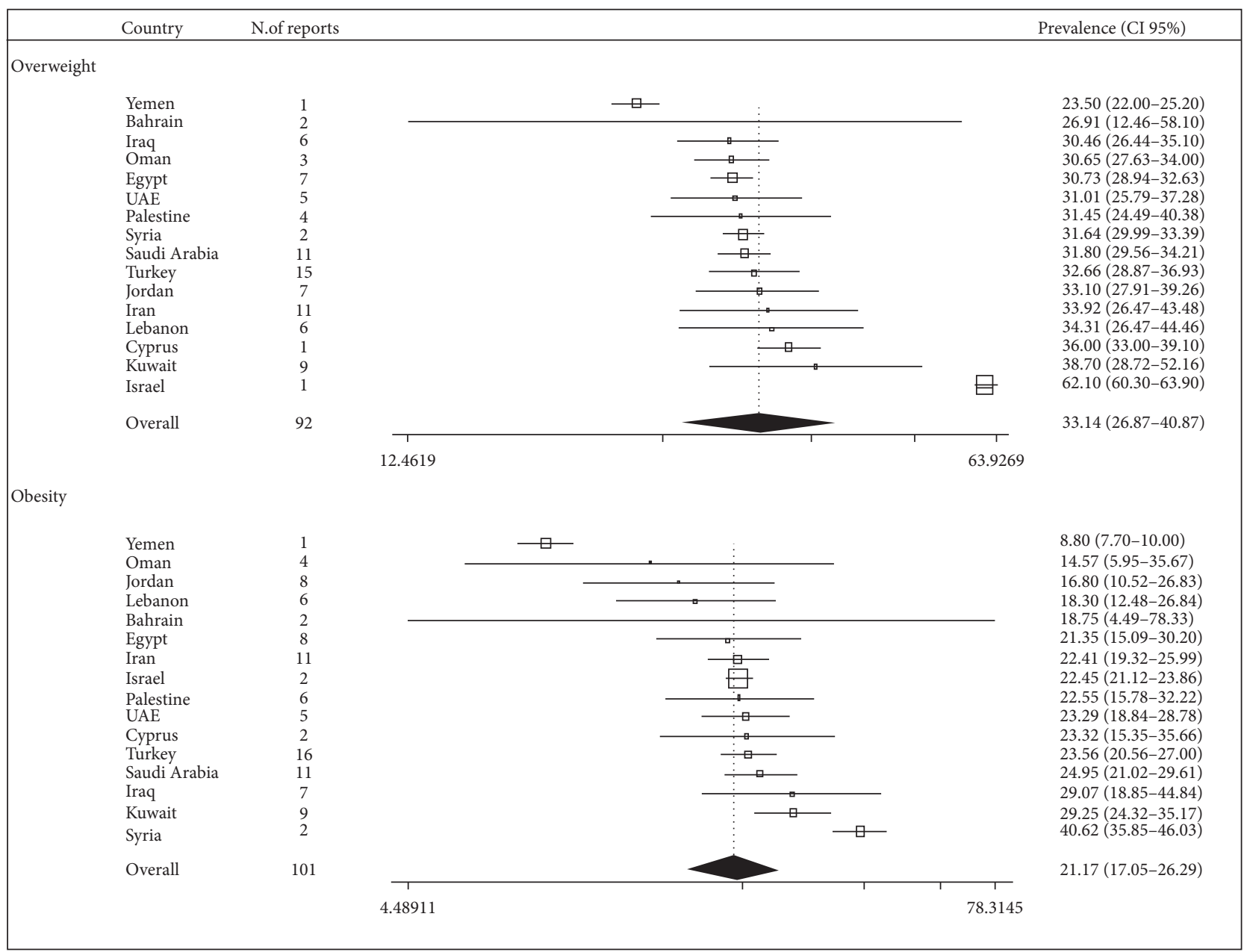

Figure 2: Overall prevalence of overweight and obesity in Middle East countries.

(PAR) for cardiovascular disease, including coronary heart disease (CHD), heart failure (HF), and atrial fibrillation (AF). Population Attributable Risk (PAR) for cardiovascular disease was ranged from 0.3 to $19.8 \%$ by countries and about $11 \%$ of $\mathrm{HF}, 4 \%$ of $\mathrm{CHD}$, and $9 \%$ of AF were related to obesity in more countries. The highest PAR was observed for heart failure (HF), of which nearly $11.5 \%$ of $\mathrm{HF}$ was attributed to obesity. Also, the cardiovascular disease burden related to obesity in Syria, Kuwait, and Iraq was higher than that in other countries due to the high prevalence of obesity in these countries. The fraction of cardiovascular disease attributable to obesity ranged from 3.6 to $10.5 \%$ in males and 4.7 to $13.4 \%$ in females.

\section{Discussion}

The results of this systematic review showed that the prevalence of overweight and obesity in the Middle East is 23.5-62.1 and 14.5-40.6, respectively. The difference in socioeconomic status and lifestyle between countries can explain this difference. In this study, the highest prevalence of obesity and overweight was in Kuwait, Syria, and Israel. Lifestyle changes over the past few years, including the use of Arabic diets (high-calorie and fatty foods such as fast foods), alcohol consumption, and reduced physical activity, may explain the high prevalence of noncommunicable diseases, including obesity [115].

Moreover, some studies have shown that the high prevalence of overweight and obesity in deprived sparsely populated groups is partly due to the low quality of their diet [116]. In this study, the lowest prevalence of obesity and overweight was in Yemen, which could be due to the low number of reports of obesity and the lack of new studies.

In this study, the prevalence of obesity was higher in women than men. This result is similar to the study in Spain [10] and contrasts with the study in Turkey [84]. This difference can be partly due to multiple births in women, hormonal differences between men and women, and sedentary lifestyle in women because most women are housewives or have jobs with less physical activity [117]. Studies have also shown that the prevalence of obesity in married people is increasing, which obviously puts women at even greater risk of obesity $[118,119]$.

Previous studies have shown that aging is strongly associated with the prevalence of obesity, and in general, the prevalence of obesity increases until age 70 and then begins to decrease $[18,120]$. The present study results also show the natural pattern of obesity increase with age, at least up to 
TABle 2: The prevalence of obesity and overweight in the Middle East countries.

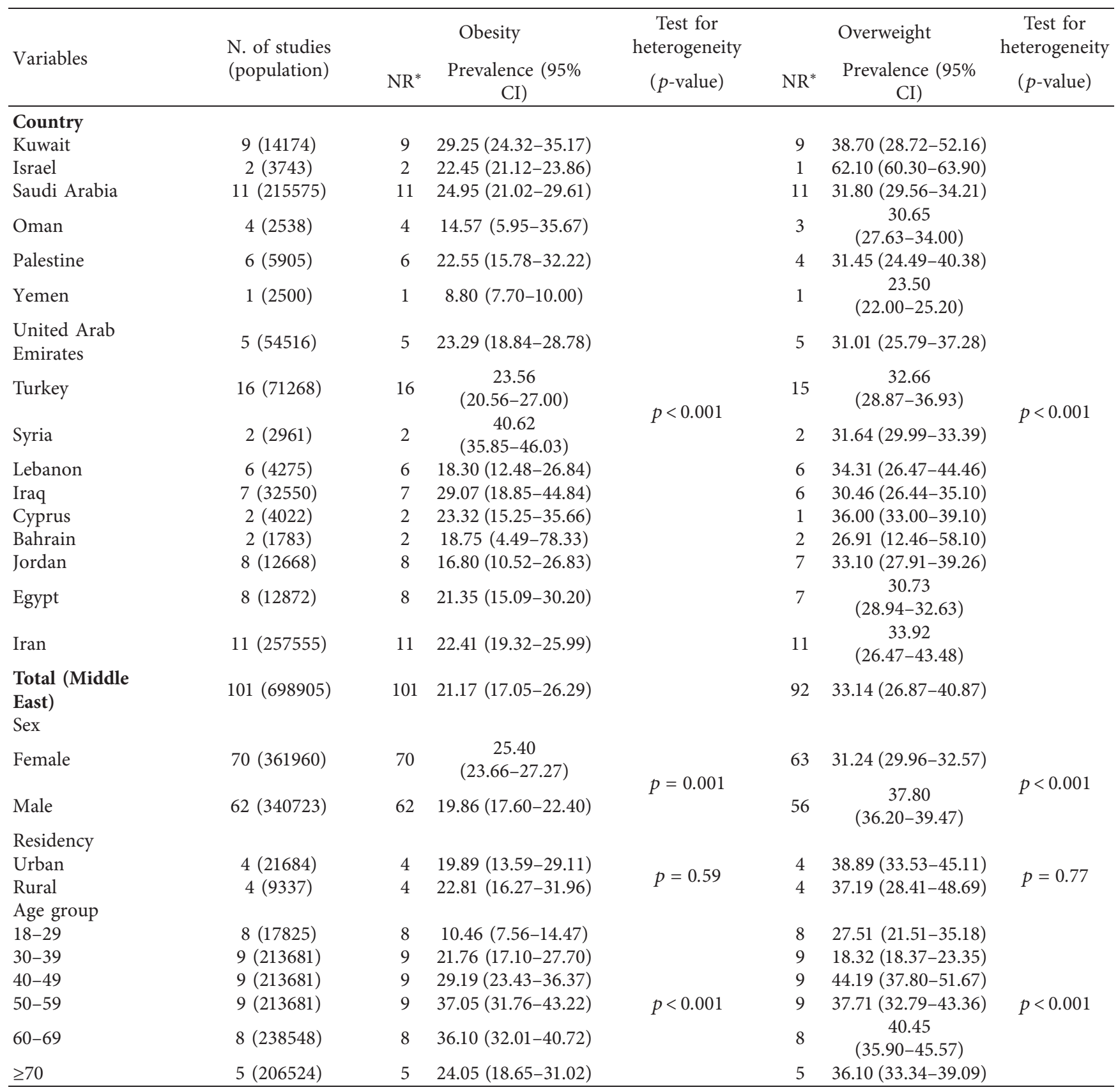

${ }^{*}$ NR: number report.

69-60 years, and the highest prevalence of obesity and overweight was seen in people over 40 years. It is thought that the decline in the prevalence of obesity in people over the age of 70 is partly due to a lower survival rate in obese people and a decrease in physical activity with increasing age in men and women. In addition, menopausal women are more prone to weight gain from 45 years $[76,121]$.

The present study showed that the prevalence of obesity and overweight in the Middle East in the last two decades had been almost a steady trend. However, the prevalence of obesity and overweight is at a high level. Evidence shows that the trend in mean BMI in northwestern European countries and high-income English-speaking regions and Asia-Pacific is flat for both sexes [122].

Furthermore, the results obtained from the Middle East region countries indicate a fundamental difference between the current level and trend of overweight and obesity between countries. In many countries, the prevalence of obesity and overweight has significantly decreased (Table 4). Another study showed that in many European countries, the prevalence of obesity and overweight in children has also stabilized [116]. While the prevalence of overweight and obesity seems to stabilize and even decline at different levels in different countries, it is still an important public health 


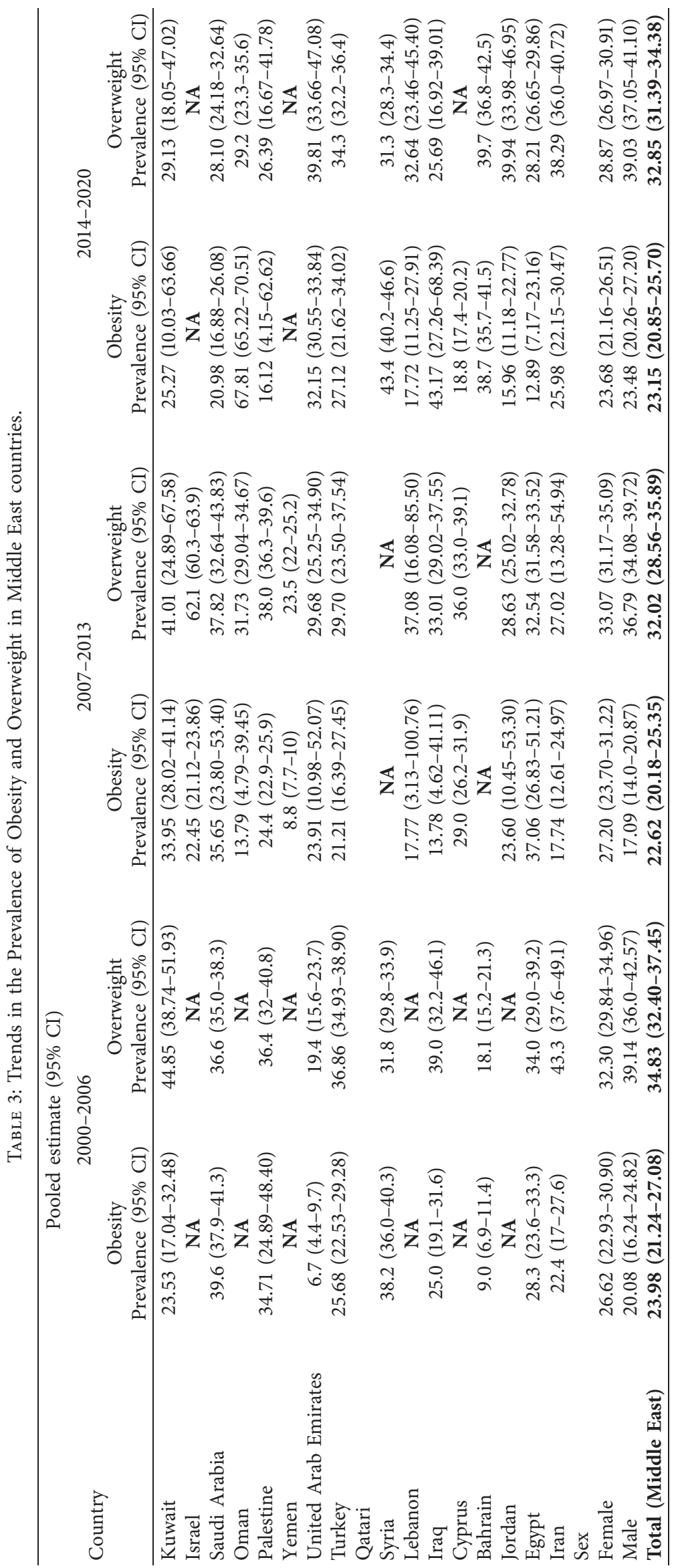


TABLe 4: Population Attributable Risk for obesity by country and cardiovascular diseases.

\begin{tabular}{|c|c|c|c|c|}
\hline \multirow{2}{*}{\multicolumn{2}{|c|}{ Variables/PAR }} & \multicolumn{3}{|c|}{ Cardiovascular diseases } \\
\hline & & Coronary heart disease (CAD) & Heart failure (HF) & Atrial fibrillation (AF) \\
\hline \multirow{16}{*}{ Countries } & Kuwait & $5.4(0.4-12.5)$ & $15.2(7.1-25.7)$ & $12.8(7.1-19.2)$ \\
\hline & Israel & $4.2(04-8.6)$ & $6.5(6.2-18.5)$ & $10.0(6.8-13.5)$ \\
\hline & Saudi Arabia & $4.5(0.4-10.6)$ & $12.9(6.2-22.3)$ & $10.9(6.8-16.4)$ \\
\hline & Oman & $2.7(0.09-12.5)$ & $7.9(1.5-25.7)$ & $6.6(1.7-19.2)$ \\
\hline & Palestine & $4.2(0.2-11.5)$ & $12.0(4.5-24.0)$ & $10.0(4.9-17.8)$ \\
\hline & Yemen & $1.5(0.1-3.9)$ & $4.7(2.1-9.0)$ & $3.9(2.3-6.3)$ \\
\hline & United Arab Emirates & $4.3(0.3-10.2)$ & $12.4(5.4-21.7)$ & $10.4(5.9-15.9)$ \\
\hline & Turkey & $4.3(0.3-9.9)$ & $12.4(6.0-21.0)$ & $10.4(6.5-15.5)$ \\
\hline & Syria & $7.4(0.6-15.8)$ & $19.8(10.0-31.2)$ & $16.9(10.9-23.8)$ \\
\hline & Lebanon & $3.4(0.2-9.6)$ & $10.0(3.6-20.4)$ & $8.4(4.0-15.0)$ \\
\hline & Iraq & $5.4(0.3-15.2)$ & $15.2(5.4-30.3)$ & $12.8(5.9-23.0)$ \\
\hline & Cyprus & $4.3(0.2-12.5)$ & $12.4(4.5-25.7)$ & $10.4(4.9-19.2)$ \\
\hline & Bahrain & $0.3(0.07-24.2)$ & $1.2(1.2-43.5)$ & $1.0(1.3-34.6)$ \\
\hline & Jordan & $3.1(0.1-9.5)$ & $9.0(3.1-20.4)$ & $7.5(3.3-15.0)$ \\
\hline & Egypt & $4.0(0.2-10.9)$ & $11.5(4.5-22.8)$ & $9.6(4.9-16.9)$ \\
\hline & Iran & $4.2(0.3-9.2)$ & $12.0(5.7-19.8)$ & $10.0(6.2-14.5)$ \\
\hline \multirow{2}{*}{ Sex } & Female & $4.7(0.4-9.9)$ & $13.4(6.8-21.0)$ & $11.3(7.4-15.5)$ \\
\hline & Male & $3.6(0.3-8.2)$ & $10.5(5.1-16.7)$ & $8.8(5.6-13.0)$ \\
\hline \multicolumn{2}{|c|}{ Total (Middle East) } & $4.0(0.3-9.6)$ & $11.5(5.1-20.4)$ & $9.6(5.6-15.0)$ \\
\hline
\end{tabular}

issue. Increasing public awareness of the effects of obesity and interventions related to daily physical activity and healthy diets have helped stabilize obesity $[116,123]$.

The present study showed that $4 \%$ of CAD, $11 \%$ of $\mathrm{HF}$, and $9 \%$ of AF in the Middle East could be attributed to obesity. In general, approximately $8 \%$ of cardiovascular diseases in the region is related to obesity. Due to the high prevalence of obesity in people over 40 years of age, the risk of developing the disease in this age group increases. Previous studies have shown a link between obesity and cardiovascular disease [124-126]. Therefore, having a healthy lifestyle that includes healthy nutrition and adequate physical activity can significantly prevent obesity and its complications such as cardiovascular disease [59].

\section{Conclusion}

This meta-analysis showed that although the prevalence of obesity and overweight has been almost constant in the Middle East over the past two decades, the prevalence of obesity is significantly higher. In addition, the high prevalence of obesity and overweight in people over 40 years of age and the increasing trend of obesity with increasing age is a concern that should be considered by providers of intervention programs in the region. The results also showed that approximately $8 \%$ of cardiovascular diseases in the Middle East could be attributed to obesity. Therefore, obesity is a risk factor for CVD, and the necessary interventions to prevent obesity and its complications are essential.

\section{Limitations}

This study had limitations such as an unequal number of studies in countries, the use of different sampling methods, and differences in the age distribution of participants, which could be the source of differences in the prevalence of obesity and overweight in countries. Another limitation of this study is the lack of reports on obesity and overweight in urban and rural areas. Also, in this study, the unadjusted relative risk was used to calculate the attributable risk, while possible confounders such as blood pressure, smoking, family history of obesity, and socioeconomic status can confound RR as an indicator of the relationship between obesity and cardiovascular disease.

\section{Data Availability}

Data are available upon request.

\section{Conflicts of Interest}

The authors declare that there are no conflicts of interest.

\section{Authors' Contributions}

Shiva Kargar and Alireza Ansari-Moghadam contributed to the conceptualization and methodology. Neda Jabbari and Shiva Kargar conducted the investigation and screening of articles. Shiva Kargar performed data extraction. Shiva Kargar and Hassan Okati-Aliabad wrote the original draft. Shiva Kargar, Hassan Okati-Aliabad, and Alireza AnsariMoghadam reviewed and edited the article.

\section{References}

[1] M. Abdelaal, C. W. le Roux, and N. G. Docherty, "Morbidity and mortality associated with obesity," Annals of Translational Medicine, vol. 5, no. 7, p. 161, 2017.

[2] D. P. Guh, W. Zhang, N. Bansback, Z. Amarsi, C. L. Birmingham, and A. H. Anis, "The incidence of comorbidities related to obesity and overweight: a systematic review and meta-analysis," BMC Public Health, vol. 9, no. 1, pp. 88-20, 2009. 
[3] H. Dai, T. A. Alsalhe, N. Chalghaf, M. Riccò, N. L. Bragazzi, and $\mathrm{J}$. Wu, "The global burden of disease attributable to high body mass index in 195 countries and territories, 1990-2017: an analysis of the Global Burden of Disease Study," PLoS Medicine, vol. 17, no. 7, p. e1003198, 2020.

[4] M. Tremmel, U.-G. Gerdtham, P. Nilsson, and S. Saha, "Economic burden of obesity: a systematic literature review," International Journal of Environmental Research and Public Health, vol. 14, no. 4, p. 435, 2017.

[5] A. H. Mokdad, C. El Bcheraoui, A. Afshin, R. Charara, I. Khalil, and M. Moradi-Lakeh, "Burden of obesity in the eastern mediterranean region: findings from the global burden of disease 2015 study," International Journal of Public Health, vol. 63, 2018.

[6] A. H. Mokdad, M. H. Forouzanfar, F. Daoud, C. El Bcheraoui, M. Moradi-Lakeh, and I. Khalil, "Health in times of uncertainty in the eastern Mediterranean region, 1990-2013: a systematic analysis for the Global Burden of Disease Study 2013," Lancet Global Health, vol. 4, no. 10, pp. e704-e13, 2016.

[7] P. Marconcin, A. Ihle, A. O. Werneck et al., "The association of healthy lifestyle behaviors with overweight and obesity among older adults from 21 countries," Nutrients, vol. 13, no. 2, p. 315, 2021.

[8] M. Ng, T. Fleming, M. Robinson, B. Thomson, N. Graetz, and C. Margono, "Global, regional, and national prevalence of overweight and obesity in children and adults during 1980-2013: a systematic analysis for the global burden of disease Study 2013," Lancet, vol. 384, no. 9945, pp. 766-781, 2014.

[9] W. H. Organization, "Obesity: preventing and managing the global epidemic,” WHO, Geneva, Switzerland, 2000.

[10] J. L. Gutiérrez-Fisac, E. López, J. R. Banegas, A. Graciani, and F. Rodríguez-Artalejo, "Prevalence of overweight and obesity in elderly people in Spain," Obesity Research, vol. 12, no. 4, pp. 710-715, 2004.

[11] D. Moher, A. Liberati, J. Tetzlaff, D. G. Altman, and P. Group, "Preferred reporting items for systematic reviews and meta-analyses: the PRISMA statement," PLoS Medicine, vol. 6, no. 7, p. e1000097, 2009.

[12] Z. Asad, M. Abbas, I. Javed, P. Korantzopoulos, and S. Stavrakis, "Obesity is associated with incident atrial fibrillation independent of gender: a meta-analysis," Journal of Cardiovascular Electrophysiology, vol. 29, no. 5, pp. 725-732, 2018.

[13] R. Mahajan, M. Stokes, A. Elliott et al., "Complex interaction of obesity, intentional weight loss and heart failure: a systematic review and meta-analysis," Heart, vol. 106, no. 1, pp. 58-68, 2020.

[14] H. Riaz, M. S. Khan, T. J. Siddiqi et al., "Association between obesity and cardiovascular outcomes," JAMA Network Open, vol. 1, no. 7, pp. e183788-e, 2018.

[15] A. Gunaid, "1187 Obesity, overweight and underweight among adults in an urban community in Yemen," Eastern Mediterranean Health Journal, vol. 18, no. 12, pp.1187-1193, 2012.

[16] M. Janghorbani, M. Amini, W. C. Willett et al., "First nationwide survey of prevalence of overweight, underweight, and abdominal obesity in Iranian adults," Obesity, vol. 15, no. 11, pp. 2797-2808, 2007.

[17] R. Kelishadi, S. Alikhani, A. Delavari, F. Alaedini, A. Safaie, and E. Hojatzadeh, "Obesity and associated lifestyle behaviours in Iran: findings from the first national non- communicable disease risk factor surveillance survey," Public Health Nutrition, vol. 11, no. 3, pp. 246-251, 2008.

[18] S. Djalalinia, S. Saeedi Moghaddam, A. Sheidaei et al., "Patterns of obesity and overweight in the Iranian population: findings of STEPs 2016," Frontiers in Endocrinology, vol. 11, p. 42, 2020.

[19] A. A. Al-Nooh, A. Abdulabbas Abdulla Alajmi, and D. Wood, "The prevalence of cardiovascular disease risk factors among employees in the Kingdom of Bahrain between October 2010 and March 2011: a cross-sectional study from a workplace health campaign," Cardiology Research and Practice, vol. 2014, 2014.

[20] M. Al-Ansari, M. Al Mannai, and A. Musaiger, "Body weight of university students in Bahrain," Bahrain Medical Bulletin, vol. 22, no. 3, 2000.

[21] D. N. Kaluski, L. Keinan-Boker, F. Stern et al., "BMI may overestimate the prevalence of obesity among women of lower socioeconomic status *," Obesity, vol. 15, no. 7, pp. 1808-1815, 2007.

[22] D. Fraser, N. Bilenko, H. Vardy et al., "Differences in food intake and disparity in obesity rates between adult Jews and Bedouins in southern Israel," Ethnicity \& Disease, vol. 18, no. 1, pp. 13-8, 2008.

[23] S. Shabu, "Prevalence of overweight/obesity and associated factors in adults in Erbil, Iraq: a household survey," Zanco Journal of Medical Sciences, vol. 23, no. 1, pp. 128-134, 2019.

[24] N. Al Tawil, M. Abdulla, and A. Abdul Ameer, "Prevalence of and factors associated with overweight and obesity among a group of Iraqi women," EMHJ-Eastern Mediterranean Health Journal, vol. 13, no. 2, pp. 420-429, 2007.

[25] A. Mansour, A. Al-Maliky, and M. Salih, "Population overweight and obesity trends of eight years in Basrah," Iraq Epidemiology.vol. 2, no. 1, p. 110, 2012.

[26] W. Ft, S. M. Hassoon, and M. A. Zadian, "Obesity and overweight among sample of foundation of technical education students in Iraq during 2011," Medical Journal of Babylon, vol. 10, no. 1, 2013.

[27] H. M. Jasim, H. M. Abdul Hussein, and E. A. Al-Kaseer, "Obesity among females in Al-Sader city Baghdad, Iraq, 2017," Journal of the Faculty of Medicine, Baghdad, vol. 60, no. 2, pp. 105-107, 2018.

[28] A. Hayyawi, K. Hasan, and R. Lafta, "Impact of nutrition clinic on obesity in Baghdad, Iraq: first year outcome," Saudi Journal of Obesity, vol. 4, no. 2, pp. 80-85, 2016.

[29] B. J. H. Al-Yasseri, A. A. Radi, and M. A. R. Abbas, "Assessment of obesity and central obesity among patients with knee osteoarthritis in Al-Sadder Hospital, Baghdad, Iraq," Journal of Ideas in Health, vol. 2, no. 2, pp. 113-117, 2019.

[30] H. Al-Kilani, M. Waly, and R. Yousef, "Trends of obesity and overweight among college students in Oman: a cross sectional study," Sultan Qaboos University Medical Journal, vol. 12, no. 1, pp. 69-76, 2012.

[31] L. Labban, "The prevalence of overweight and obesity among A'Sharqiyah university students in sultanate of Oman: a randomized study," EC Nutrition, vol. 3, pp. 521-527, 2015.

[32] M. N. Barakat and R. M. Youssef, "Prevalence of dysglycemia and other cardiovascular risk factors among the rural population of Oman," Hypertension, vol. 129, no. 85, pp. 14-17, 2008.

[33] T. Man, I. M. Nolte, D. Jaju et al., "Heritability and genetic correlations of obesity indices with ambulatory and office beat-to-beat blood pressure in the Oman Family Study," Journal of Hypertension, vol. 38, no. 8, pp. 1474-1480, 2020. 
[34] Z. Abdeen, C. Jildeh, S. Dkeideek, R. Qasrawi, I. Ghannam, and H. Al Sabbah, "Overweight and obesity among Palestinian adults: analyses of the anthropometric data from the first national health and nutrition survey (1999-2000)," Journal of obesity, vol. 2012, p. 213547, 2012.

[35] H. Abdul-Rahim, N. Abu-Rmeileh, A. Husseini, G. Holmboe-Ottesen, J. Jervell, and E. Bjertness, "Obesity and selected co-morbidities in an urban Palestinian population," International Journal of Obesity, vol. 25, no. 11, pp. 1736-1740, 2001.

[36] R. R. El Kishawi, K. L. Soo, Y. A. Abed, and W. A. M. W. Muda, "Obesity and overweight: prevalence and associated socio demographic factors among mothers in three different areas in the Gaza Strip-Palestine: a crosssectional study," BMC obesity, vol. 1, no. 1, pp. 1-7, 2014.

[37] L. Stene, R. Giacaman, H. Abdul-Rahim, A. Husseini, K. Norum, and G. Holmboe-Ottesen, "Obesity and associated factors in a Palestinian West Bank village population," European Journal of Clinical Nutrition, vol. 55, no. 9, pp. 805-811, 2001.

[38] B. Damiri, A. Aghbar, S. Alkhdour, and Y. Arafat, "Characterization and prevalence of metabolic syndrome among overweight and obese young Palestinian students at AnNajah National University," Diabetes \& Metabolic Syndrome: Clinical Research Reviews, vol. 12, no. 3, pp. 343-348, 2018.

[39] R. El Kishawi, K. L. Soo, Y. Abed, and W. A. M. W. Muda, "Epidemic of obesity among mothers in the gaza stripPalestine," Journal of Emergency Medicine, Trauma and Acute Care, vol. 2016, 2016.

[40] E. Weiderpass, E. Botteri, J. C. Longenecker et al., "The prevalence of overweight and obesity in an adult Kuwaiti population in 2014," Frontiers in Endocrinology, vol. 10, p. $449,2019$.

[41] I. Al Rashdan and Y. Al Nesef, "Prevalence of overweight, obesity, and metabolic syndrome among adult Kuwaitis: results from community-based national survey," Angiology, vol. 61, no. 1, pp. 42-48, 2010.

[42] H. T. AlMajed, A. T. Al Attar, A. A. Sadek, T. A. AlMuaili, O. A. AlMutairi, and A. S. Shaghouli, "Prevalence of dyslipidemia and obesity among college students in Kuwait," Alexandria Journal of Medicine, vol. 47, no. 1, 2011.

[43] S. R. Raman, B. Al-Halabi, E. Hamdan, and M. D. Landry, "Prevalence and risk factors associated with self-reported carpal tunnel syndrome (CTS) among office workers in Kuwait," BMC Research Notes, vol. 5, no. 1, pp. 289-296, 2012.

[44] T. Al-Asi, "Overweight and obesity among Kuwait Oil Company employees: a cross-sectional study," Occupational Medicine, vol. 53, no. 7, pp. 431-435, 2003.

[45] H. E. Badr, N. M. Shah, and M. A. Shah, "Obesity among Kuwaitis aged 50 years or older: prevalence, correlates, and comorbidities," The Gerontologist, vol. 53, no. 4, pp. 555-566, 2013.

[46] D. Alkazemi, "Gender differences in weight status, dietary habits, and health attitudes among college students in Kuwait: a cross-sectional study," Nutrition and Health, vol. 25, no. 2, pp. 75-84, 2019.

[47] A. N. Al-Isa, "Factors associated with overweight and obesity among Kuwaiti kindergarten female teachers," Nutrition and Health, vol. 18, no. 1, pp. 67-71, 2004.

[48] S. Zaghloul, S. N. Al-Hooti, N. Al-Hamad et al., "Evidence for nutrition transition in Kuwait: over-consumption of macronutrients and obesity," Public Health Nutrition, vol. 16, no. 4, pp. 596-607, 2013.
[49] M. A. Bakir, K. Hammad, and L. Mohammad, "Prevalence of obesity, central obesity, and associated socio-demographic variables in Syrian women using different anthropometric indicators," Anthropological Review, vol. 80, no. 2, pp. 191-205, 2017.

[50] M. F. Fouad, S. Rastam, K. D. Ward, and W. Maziak, "Prevalence of obesity and its associated factors in Aleppo, Syria," Global Heart, vol. 2, no. 2, pp. 85-94, 2006.

[51] E. Andreou, P. Hajigeorgiou, K. Kyriakou et al., "Risk factors of obesity in a cohort of 1001 Cypriot adults: an epidemiological study," Hippokratia, vol. 16, no. 3, pp. 256-60, 2012.

[52] A. Heracldes, O. Kolokotroni, and A. Charalambous, "Sociodemographic determinants of obesity in a cross-sectional study of adults in CyprusAlexandros Heraclides," The European Journal of Public Health, vol. 25, 2015.

[53] A. Abu-Zaiton and A. Al-Fawwaz, "Prevalence of diabetes, obesity, hypertension and associated factors among students of Al-albayt University, Jordan," World Journal of Medical Sciences, vol. 9, no. 1, pp. 49-54, 2013.

[54] A. A. Suleiman, O. K. Alboqai, N. Yasein, J. M. El-Qudah, M. a. F. Bataineh, and B. A. Obeidat, "Prevalence of and factors associated with overweight and obesity among Jordan University students," Journal of Biological Sciences, vol. 9, no. 7, pp. 738-745, 2009.

[55] O. Atoom, "Prevalence of obesity and overweight among military personnel in north of Jordan and some associated risk factors," JRMS, vol. 25, no. 2, pp. 19-26, 2018.

[56] Y. S. Khader, H. A. Bawadi, T. F. Haroun, M. Alomari, and R. F. Tayyem, "The association between periodontal disease and obesity among adults in Jordan," Journal of Clinical Periodontology, vol. 36, no. 1, pp. 18-24, 2009.

[57] L. M. Matalqah, K. M. Radaideh, and R. H. Thabet, "Impact of chronic disorders and obesity on quality of life in Northern Jordan," Journal of Public Health, vol. 29, pp. 1-7, 2019.

[58] M. N. Ahmad, S. K. Tukan, and H. R. Takruri, "Obesity and overweight in young adult females of Northern Badia of Jordan," Malaysian Journal of Nutrition, vol. 12, no. 2, pp. 157-166, 2006.

[59] A. Khamaiseh and M. Al Bashtawy, "Prevalence of obesity and physical inactivity behaviors among nursing students in Mutah University, Jordan," World Journal of Medical Sciences, vol. 12, no. 2, pp. 95-102, 2015.

[60] L. Abu Ghazaleh and Z. Budair, "The relation between stone disease and obesity in Jordan," Saudi Journal of Kidney Diseases and Transplantation, vol. 24, no. 3, p. 610, 2013.

[61] J. F. Alarjan, O. S. Hindawi, L. W. Judge, Z. A. Aleyadh, and D. M. Bellar, "Prevalence of obesity and behaviors associated with the development of metabolic disease among medical practitioners in Jordan," Journal of Education and Health Promotion, vol. 4, p. 17, 2015.

[62] M. Mowafi, Z. Khadr, I. Kawachi, S. V. Subramanian, A. Hill, and G. G. Bennett, "Socioeconomic status and obesity in Cairo, Egypt: a heavy burden for all," Journal of epidemiology and global health, vol. 4, no. 1, pp. 13-21, 2014.

[63] H. A. Abdel Sadek, M. W. Abu-Nazel, Z. N. Shata, and N. K. Abd El-Fatah, "The relationship between the BMI and the emotional status of Alexandria University students, Egypt," Journal of the Egyptian Public Health Association, vol. 91, no. 3, pp. 101-108, 2016.

[64] A. M. Shebl, E. S. Z. Hatata, A. M. Boughdady, and S. M. ElSayed, "Prevalence and risk factors of obesity among elderly attending geriatric outpatient clinics in mansoura city," 
Journal of Education and Practice, vol. 6, no. 30, pp. 136-147, 2015.

[65] T. A. A. Rahman, E. M. Mahfouz, and E. S. Mohammed, "Prevalence and comorbidities of overweight and obesity among elderly population residing a rural community, Minia, Egypt," Egyptian Journal of Community Medicine, vol. 30, no. 4, 2012.

[66] D. M. Genena and A. A. Salama, "Obesity and eating habits among university students in Alexandria, Egypt: a cross sectional study," World journal of nutrition and health, vol. 5, no. 3, pp. 62-68, 2017.

[67] A. Farrag, A. Eraky, W. Aroussy, G. Sayed, and A. Mahrous, "Obesity and other cardiovascular risk factors in Egyptian University Students: magnitude of the problem," Epidemiology, vol. 5, no. 181, pp. 2161-1165, 2015.

[68] E. M. Mahfouz, E. Sameh, and T. Areny, Prevalence and Correlates of Overweight and Obesity Among Elderly Population Residing a Rural Community, Minia, Egypt, Faculty of medicine, Minia University, Minya, Egypt, 2006.

[69] K. M. Yount and L. Li, "Domestic violence and obesity in Egyptian women," Journal of Biosocial Science, vol. 43, no. 1, pp. 85-99, 2011.

[70] F. Sakr, M. Dabbous, J. Safwan, M. Akel, and M. Cherfan, "Overweight And obesity: young population concerns IN the LEBANESE community,” Therapy, vol. 7, p. 8, 2016.

[71] I. Fahs, Z. Khalife, D. Malaeb, M. Iskandarani, and P. Salameh, "The prevalence and awareness of cardiovascular diseases risk factors among the Lebanese population: a prospective study comparing urban to rural populations," Cardiology Research and Practice, vol. 2017, Article ID 3530902, 10 pages, 2017.

[72] F. Naja, L. Nasreddine, L. Itani et al., "Dietary patterns and their association with obesity and sociodemographic factors in a national sample of Lebanese adults," Public Health Nutrition, vol. 14, no. 9, pp. 1570-1578, 2011.

[73] N. Yahia, A. Achkar, A. Abdallah, and S. Rizk, "Eating habits and obesity among Lebanese university students," Nutrition Journal, vol. 7, no. 1, pp. 32-36, 2008.

[74] A. Haidar, L. Jouni, M. Koubar, S. Daouk, and M. Hoteit, "Impact of active smoking, passive smoking, and smoking cessation on overweight and obesity: first national crosssectional study," International Journal of Medical Science and Public Health, vol. 6, no. 3, p. 1, 2017.

[75] Z. Samhat, R. Attieh, and Y. Sacre, "Relationship between night shift work, eating habits and BMI among nurses in Lebanon," BMC Nursing, vol. 19, pp. 25-26, 2020.

[76] T. Delibasi, Y. Karaaslan, I. Ustun, E. Koroglu, and S. Hosgor, "National prevalence of underweight, overweight and obesity in Turkey: cross sectional study of a representative adult population," Open Medicine, vol. 2, no. 3, pp. 294-303, 2007.

[77] C. Erem, R. Yildiz, H. Kavgaci et al., "Prevalence of diabetes, obesity and hypertension in a Turkish population (Trabzon city)," Diabetes Research and Clinical Practice, vol. 54, no. 3, pp. 203-208, 2001.

[78] V. D. Yumuk, H. Hatemi, T. Tarakci et al., "High prevalence of obesity and diabetes mellitus in Konya, a central Anatolian city in Turkey," Diabetes Research and Clinical Practice, vol. 70, no. 2, pp. 151-158, 2005.

[79] E. Akbay, R. Bugdayci, H. Tezcan, K. Konca, A. Yazar, and C. Pata, "The prevalence of obesity in adult population in a city on the Mediterranean coast of Turkey," Turkish Journal of Endocrinology and Metabolism, vol. 1, pp. 31-35, 2003.
[80] N. Bagriacik, H. Onat, B. Ilhan, T. Tarakci, Z. Oşar, and M. Ozyazar, "Obesity profile in Turkey," International Journal of Diabetes and Metabolism, vol. 17, no. 1, pp. 5-8, 2009.

[81] T. Gultekin, B. K. Ozer, G. Akin, Y. Bektas, M. Sagir, and E. Gulec, "Prevalence of overweight and obesity in Turkish adults," Anthropologischer Anzeiger, vol. 67, pp. 205-212, 2009.

[82] M. Ardahan and E. Konal, "The prevalence of hypertension and obesity and effective factors: a cross-sectional bazaar study," JPMA The Journal of the Pakistan Medical Association, vol. 69, no. 7, pp. 1018-1021, 2019.

[83] I. Arikan, K. Karakaya, M. Erata et al., "Fighting obesity campaign in Turkey: evaluation of media campaign efficacy," Central European Journal of Public Health, vol. 22, no. 3, pp. 170-4, 2014.

[84] Y. Ustu, M. Ugurlu, O. Aslan et al., "High prevalence of obesity in Tokat, a northern province of Turkey," JPMA. The Journal of the Pakistan Medical Association, vol. 62, no. 435, pp. 435-440, 2012.

[85] N. Yabanci, E. Gocgeldi, I. Simsek, and S. Kilic, "Prevalence of obesity, abdominal obesity and the associated factors among a group of Turkish adults," Pakistan Journal of Medical Sciences, vol. 26, no. 1, pp. 21-25, 2010.

[86] H. Şahin, B. Çiçek, M. Yılmaz, D. Ongan, N. İnanç, and M. Aykut, "Obesity prevalence, waist-to-height ratio and associated factors in adult Turkish males," Obesity Research \& Clinical Practice, vol. 5, no. 1, pp. e29-e35, 2011.

[87] C. Erem, C. Arslan, A. Hacihasanoglu et al., "Prevalence of obesity and associated risk factors in a Turkish population (Trabzon city, Turkey)," Obesity Research, vol. 12, no. 7, pp. 1117-1127, 2004.

[88] G. Dinç, E. Eser, G. L. Saatli et al., "The relationship between obesity and health related quality of life of women in a Turkish city with a high prevalence of obesity," Asia Pacific Journal of Clinical Nutrition, vol. 15, no. 4, pp. 508-15, 2006.

[89] B. M. Yalcin, E. M. Sahin, and E. Yalcin, "Prevalence and epidemiological risk factors of obesity in Turkey," Middle East Journal of Family Medicine, vol. 6, no. 6, pp. 1-2, 2004.

[90] O. Ucan and N. Ovayolu, "Relationship between diabetes mellitus, hypertension and obesity, and health-related quality of life in Gaziantep, a central south-eastern city in Turkey," Journal of Clinical Nursing, vol. 19, no. 17-18, pp. 2511-2519, 2010.

[91] A. Kerkadi, "Evaluation of nutritional status of United Arab Emirates University female students," Emirates Journal of Food and Agriculture, vol. 15, no. 2, pp. 42-50, 2003.

[92] R. Kalavathy, S. A. Al Araj, and S. A. Rabbani, "Prevalence of obesity among adults in Ras Al Khaimah, United Arab Emirates," International Journal of Research in Medical Sciences, vol. 7, no. 2, p. 555, 2019.

[93] C. Hajat, O. Harrison, and Z. Al Siksek, "Weqaya: a population-wide cardiovascular screening program in Abu Dhabi, United Arab Emirates," American Journal of Public Health, vol. 102, no. 5, pp. 909-914, 2012.

[94] N. Sulaiman, S. Elbadawi, A. Hussein et al., "Prevalence of overweight and obesity in United Arab Emirates Expatriates: the UAE national diabetes and lifestyle study," Diabetology \& Metabolic Syndrome, vol. 9, no. 1, pp. 88-89, 2017.

[95] L. I. Sheikh-Ismail, C. J. K. Henry, H. J. Lightowler, A. S. Aldhaheri, E. Masuadi, and H. M. Al Hourani, "Prevalence of overweight and obesity among adult females in the United Arab Emirates," International Journal of Food Sciences and Nutrition, vol. 60, no. sup3, pp. 26-33, 2009. 
[96] M. A. Alhakbany, H. A. Alzamil, W. A. Alabdullatif, S. N. Aldekhyyel, M. N. Alsuhaibani, and H. M. Al-Hazzaa, "Lifestyle habits in relation to overweight and obesity among Saudi women attending health science Colleges," Journal of epidemiology and global health, vol. 8, no. 1-2, pp. 13-19, 2018.

[97] A. S. Al-Rethaiaa, A.-E. A. Fahmy, and N. M. Al-Shwaiyat, "Obesity and eating habits among college students in Saudi Arabia: a cross sectional study," Nutrition Journal, vol. 9, no. 1, pp. 1-10, 2010.

[98] N. A. Al-Baghli, A. J. Al-Ghamdi, K. A. Al-Turki, A. G. ElZubaier, M. M. Al-Ameer, and F. A. Al-Baghli, "Overweight and obesity in the eastern province of Saudi Arabia," Saudi Medical Journal, vol. 29, no. 9, pp. 1319-1325, 2008.

[99] A. M. Al-Qahtani, "Prevalence and predictors of obesity and overweight among adults visiting primary care settings in the Southwestern region, Saudi Arabia," BioMed Research International, vol. 2019, Article ID 8073057, 5 pages, 2019.

[100] M. A. Alsaif, I. A. Hakim, R. B. Harris et al., "Prevalence and risk factors of obesity and overweight in adult Saudi population," Nutrition Research, vol. 22, no. 11, pp. 1243-1252, 2002.

[101] B. Horaib, H. I. Al-Khashan, A. M. Mishriky, M. A. Selim, N. AlNowaiser, and A. A. BinSaeed, "Prevalence of obesity among military personnel in Saudi Arabia and associated risk factors," Saudi Medical Journal, vol. 34, no. 4, pp. 401407, 2013.

[102] M. Baig, Z. J. Gazzaz, M. A. Gari, H. G. Al-Attallah, K. S. AlJedaani, and A. T. Mesawa, "Prevalence of obesity and hypertension among University students' and their knowledge and attitude towards risk factors of cardiovascular disease (CVD) in Jeddah, Saudi Arabia," Pakistan journal of medical sciences, vol. 31, no. 4, p. 816, 2015.

[103] S. Al-Ghamdi, M. M. Shubair, A. Aldiab, J. M. Al-Zahrani, K. K. Aldossari, and M. Househ, "Prevalence of overweight and obesity based on the body mass index; a cross-sectional study in Alkharj, Saudi Arabia," Lipids in Health and Disease, vol. 17, no. 1, pp. 1-8, 2018.

[104] F. S. Alharthi, J. S. Alrahimi, A. A. Alotaibi, D. A. Alhamdi, B. M. Ibrahim, and Y. A. Badeeb, "Prevalence of undiagnosed cardiovascular risk factors in adults aged 20 - 40: a crosssectional study in 2016 in jeddah, Saudi Arabia," Cardiology research, vol. 8, no. 3, pp. 111-116, 2017.

[105] M. J. Balgoon, M. H. Al-Zahrani, N. A. Alkhattabi, and N. A. Alzahrani, "The correlation between obesity and metabolic syndrome in young female university students in the Kingdom of Saudi Arabia," Diabetes \& Metabolic Syndrome: Clinical Research Reviews, vol. 13, no. 4, pp. 23992402, 2019.

[106] R. Al-Raddadi, S. M. Bahijri, H. A. Jambi, G. Ferns, and J. Tuomilehto, "The prevalence of obesity and overweight, associated demographic and lifestyle factors, and health status in the adult population of Jeddah, Saudi Arabia," Therapeutic advances in chronic disease, vol. 10, p. 2040622319878997, 2019.

[107] J. S. Tabrizi, H. Sadeghi-Bazargani, M. Farahbakhsh, L. Nikniaz, and Z. Nikniaz, "Prevalence and associated factors of overweight or obesity and abdominal obesity in Iranian population: a population-based study of northwestern Iran," Iranian Journal of Public Health, vol. 47, no. 10, pp. 1583-1592, 2018.

[108] S. B. Ghaderian, L. Yazdanpanah, H. Shahbazian, A. R. Sattari, S. M. Latifi, and S. Sarvandian, "Prevalence and correlated factors for obesity, overweight and central obesity in southwest of Iran," Iranian Journal of Public Health, vol. 48, no. 7, pp. 1354-1361, 2019.

[109] M. Rezaeian and Z. Salem, "Prevalence of obesity and abdominal obesity in a sample of urban adult population within South East of Iran," Pakistan journal of medical sciences, vol. 23, no. 2, p. 193, 2007.

[110] S. M. T. Ayatollahi and Z. Ghoreshizadeh, "Prevalence of obesity and overweight among adults in Iran," Obesity Reviews, vol. 11, no. 5, pp. 335-337, 2010.

[111] B. Nikooyeh, Z. Abdollahi, F. Salehi, S. Nourisaeidlou, M. Hajifaraji, and M. Zahedirad, "Prevalence of obesity and overweight and its associated factors in urban adults from west azerbaijan, iran: the national food and nutritional surveillance program (nfnsp)," Nutrition and Food Sciences Research, vol. 3, 2016.

[112] S. Dastgiri, R. Mahdavi, H. Tu Tunchi, and E. Faramarzi, "Prevalence of obesity, food choices and socio-economic status: a cross-sectional study in the north-west of Iran," Public Health Nutrition, vol. 9, no. 8, pp. 996-1000, 2006.

[113] F. Najafi, S. Soltani, B. Karami Matin et al., "Socioeconomicrelated inequalities in overweight and obesity: findings from the Persian cohort study," BMC Public Health, vol. 20, no. 1, pp. 214-313, 2020.

[114] A. Marzban, A. Nadjarzadeh, M. Abbasi-Shavazi, M.-R. Rezaei, S. Jambarsang, and M.-H. Ehrampoush, "Prevalence of overweight, obesity, and its related factors in adult population of yazd," Journal of Nutrition and Food Security, vol. 5, no. 3, pp. 192-200, 2020.

[115] M. Batal, L. Steinhouse, and H. Delisle, "The nutrition transition and the double burden of malnutrition," Médecine et Santé Tropicales, vol. 28, no. 4, pp. 345-350, 2018.

[116] M. Garrido-Miguel, I. Cavero-Redondo, C. Álvarez-Bueno, F. Rodríguez-Artalejo, L. A. Moreno, and J. R. Ruiz, "Prevalence and trends of overweight and obesity in European children from 1999 to 2016: a systematic review and meta-analysis," JAMA Pediatrics, vol. 173, no. 10, p. e192430e, 2019.

[117] A. Vaisi-Raygani, M. Mohammadi, R. Jalali, A. Ghobadi, and N. Salari, "The prevalence of obesity in older adults in Iran: a systematic review and meta-analysis," BMC Geriatrics, vol. 19, no. 1, pp. 1-9, 2019.

[118] A. R. Gavin, G. E. Simon, and E. J. Ludman, "The association between obesity, depression, and educational attainment in women: the mediating role of body image dissatisfaction," Journal of Psychosomatic Research, vol. 69, no. 6, pp. 573$581,2010$.

[119] F. Rahmati, T. Y. Moghadass, M. Shidfar, F. Habibi, and M. Jafari, "Prevalence of obesity and hypertension among Tehran University students," Pakistan Journal of Medical Sciences, vol. 3, 2004.

[120] L. Keinan-Boker, N. Noyman, A. Chinich, M. Green, and D. Nitzan-Kaluski, "Overweight and obesity prevalence in Israel: findings of the first national health and nutrition survey (MABAT)," Schweizer Archiv fuer Tierheilkunde, vol. 31, p. 19, 2005.

[121] W. Jia, K. Xiang, L. Chen, J. Lu, and Y. Wu, "Epidemiological study on obesity and its comorbidities in urban Chinese older than 20 years of age in Shanghai, China," Obesity Reviews, vol. 3, no. 3, pp. 157-165, 2002.

[122] L. Abarca-Gómez, Z. A. Abdeen, Z. A. Hamid, N. M. AbuRmeileh, B. Acosta-Cazares, and C. Acuin, "Worldwide trends in body-mass index, underweight, overweight, and obesity from 1975 to 2016: a pooled analysis of 2416 population-based measurement studies in 1289 million 
children, adolescents, and adults," The Lancet, vol. 390, no. 10113, pp. 2627-2642, 2017.

[123] T. Olds, C. Maher, S. Zumin et al., "Evidence that the prevalence of childhood overweight is plateauing: data from nine countries," International Journal of Pediatric Obesity: IJPO: an official journal of the International Association for the Study of Obesity, vol. 6, no. 5-6, pp. 342-360, 2011.

[124] J. Opio, E. Croker, G. S. Odongo, J. Attia, K. Wynne, and M. McEvoy, "Metabolically healthy overweight/obesity are associated with increased risk of cardiovascular disease in adults, even in the absence of metabolic risk factors: a systematic review and meta-analysis of prospective cohort studies," Obesity Reviews, vol. 21, no. 12, p. e13127, 2020.

[125] A. K. Dwivedi, P. Dubey, D. P. Cistola, and S. Y. Reddy, "Association between obesity and cardiovascular outcomes: updated evidence from meta-analysis studies," Current Cardiology Reports, vol. 22, no. 4, pp. 25-19, 2020.

[126] S. M. Artham, C. J. Lavie, R. V. Milani, and H. O. Ventura, "Obesity and hypertension, heart failure, and coronary heart disease-risk factor, paradox, and recommendations for weight loss," The Ochsner Journal, vol. 9, no. 3, pp. 124-132, 2009. 